\title{
Metabolic syndrome in polycystic ovary syndrome: a review
}

\author{
Kalaivani V., Ushadevi Gopalan*
}

Department of Obstetrics and Gynaecology, Shri Sathya Sai Medical College and Research Institute, Tamil Nadu, India

Received: 11 January 2021

Accepted: 10 February 2021

\section{* Correspondence:}

Dr. Ushadevi Gopalan,

E-mail: ushag7@hotmail.com

Copyright: (C) the author(s), publisher and licensee Medip Academy. This is an open-access article distributed under the terms of the Creative Commons Attribution Non-Commercial License, which permits unrestricted non-commercial use, distribution, and reproduction in any medium, provided the original work is properly cited.

\section{ABSTRACT}

Polycystic ovary syndrome is one of the most common endocrine abnormalities in women. It affects both reproductive life and overall health of the women including metabolic abnormalities. A multidisciplinary approach is needed in those with metabolic variations to prevent them from the long-term complications like cardiovascular diseases and diabetes mellitus. The objective of this article is to review the association between PCOS and metabolic syndrome.

Keywords: Polycystic ovary syndrome, Metabolic syndrome, Insulin resistance, Dyslipidaemia, Hyperandrogenism

\section{INTRODUCTION}

One of the most common endocrine disorders encountered in the reproductive women nowadays is polycystic ovary syndrome with a prevalence ranging from $6-15 \%$ worldwide. ${ }^{1}$ Polycystic ovary syndrome was described by Stein and Leventhal in the year 1935 and hence it is also called as Stein Leventhal syndrome. ${ }^{2}$ Various factors contribute to the development of PCOS in women but the exact etiology for this disorder is not clearly understood. ${ }^{3}$ PCOS leads to various complications like metabolic, endocrine, reproductive, psychological disturbances and increased risk of developing endometrial carcinoma. ${ }^{4}$ Metabolic complications are due to insulin resistance, hyperinsulinemia, hyperandrogenism and obesity.

PCOS women are at increased risk of developing type II diabetes and impaired glucose tolerance. ${ }^{5}$ Metabolic syndromes is a group of disorders which include cardiovascular diseases and diabetes mellitus. The common underlying pathophysiology of PCOS and metabolic syndrome is insulin resistance. ${ }^{6}$ The prevalence of metabolic syndrome in PCOS women is about $33 \%$. Few studies have shown that insulin resistance in PCOS plays an important role in the development of metabolic syndrome irrespective of lean or obese status of the women. ${ }^{8}$ The risk of diabetes increases in those PCOS women with family history of diabetes. ${ }^{9}$

\section{CRITERIA TO DEFINE METABOLIC SYNDROME}

There are various criteria that are used to define metabolic syndrome,

Table 1: International diabetes federation (IDF) 2006.

International diabetes federation (IDF) $2006^{10}$

Waist circumference more than $80 \mathrm{cms}$ is a definitive parameter Along with the presence of two or more of the following :

1 Blood glucose $>100 \mathrm{mg} / \mathrm{dl}(5.6 \mathrm{mmol} / \mathrm{L})$ or diagnosed diabetes

2 HDL cholesterol $<50 \mathrm{mg} / \mathrm{dl}(1.3 \mathrm{mmol} / \mathrm{L})$ or drug treatment for low HDL cholesterol

3 Blood triglycerides $>150 \mathrm{mg} / \mathrm{dl}(1.7 \mathrm{mmol} / \mathrm{L})$ or drug treatment for elevated triglycerides

4 Blood pressure $>130 / 85 \mathrm{mmHg}$ or drug treatment for hypertension. 
Table 2: World Health Organisation (WHO) 1999.

\begin{tabular}{|l|l|}
\hline World Health Organisation (WHO ) $1999^{11}$ \\
\hline $\begin{array}{l}\text { Plasma glucose }>\mathbf{1 1 0 m g} / \mathbf{d l}(\mathbf{6 . 1} \mathbf{~ m m o l} / \mathrm{L}), 2 \text {-hour } \\
\text { glucose }>\mathbf{1 4 0 m g} / \mathbf{d l}(\mathbf{7 . 8} \mathbf{~ m m o l} / \mathrm{L}) \text { or presence of insulin } \\
\text { resistance, along with } \mathbf{2} \text { or more of the following }\end{array}$ \\
\hline $\mathbf{1}$ & $\begin{array}{l}\text { High density lipoprotein }(\mathrm{HDL}) \text { cholesterol }<1.0 \\
\text { mmol/L }(<40 \mathrm{mg} / \mathrm{dl})\end{array}$ \\
\hline $\mathbf{2}$ & Serum. triglycerides $1.7 \mathrm{mmol} / \mathrm{L}(>150 \mathrm{mg} / \mathrm{dl})$ \\
\hline $\mathbf{3}$ & BMI $>30 \mathrm{~kg} / \mathrm{m} 2$ or waist hip ratio $>0.85$ \\
\hline $\mathbf{4}$ & Blood pressure $>140 / 90 \mathrm{mmHg}$. \\
\hline
\end{tabular}

Table 3: National cholesterol education program (NCEP).

\begin{tabular}{|l|l|}
\hline National cholesterol education program (NCEP) & ${ }^{12}$ \\
\hline $\begin{array}{l}\text { 3 or more of the following parameter should be } \\
\text { fulfilled }\end{array}$ \\
\hline $\mathbf{1}$ & $\begin{array}{l}\text { Blood glucose }>100 \mathrm{mg} / \mathrm{dl}(5.6 \mathrm{mmol} / \mathrm{L}) \text { or drug } \\
\text { treatment for elevated blood glucose }\end{array}$ \\
\hline $\mathbf{2}$ & $\begin{array}{l}\mathrm{HDL} \text { cholesterol }<50 \mathrm{mg} / \mathrm{dl}(1.3 \mathrm{mmol} / \mathrm{L}) \text { or drug } \\
\text { treatment for low HDL cholesterol }\end{array}$ \\
\hline $\mathbf{3}$ & $\begin{array}{l}\text { Blood triglycerides }>150 \mathrm{mg} / \mathrm{dl}(1.7 \mathrm{mmol} / \mathrm{L}) \text { or drug } \\
\text { treatment for elevated triglycerides }\end{array}$ \\
\hline $\mathbf{4}$ & Waist circumference $>88 \mathrm{cms}$ \\
\hline $\mathbf{5}$ & $\begin{array}{l}\text { Blood pressure }>130 / 85 \mathrm{mmHg} \text { or drug treatment for } \\
\text { hypertension. }\end{array}$ \\
\hline
\end{tabular}

\section{METABOLIC ABNORMALITIES}

Metabolism of carbohydrates, proteins, lipid, amino acid and purines are disturbed in PCOS. ${ }^{13}$ This leads to a range of metabolic abnormalities in PCOS women. The pathogenesis of metabolic syndrome is influenced by both genetic and life style factors. ${ }^{14}$ The prevalence of metabolic syndrome varies in different regions of the world based on age, race, gender, ethnicity and the different criteria that are used to diagnose. ${ }^{15}$

\section{DIABETES}

Insulin resistance plays an important role in the development of diabetes mellitus in PCOS women due to the release of excessive free fatty acids. This is due to defect in post receptor signalling pathway associated with auto phosphorylation of the insulin receptor. ${ }^{16}$ Free fatty acids are toxic to beta cells of pancreas leading to decrease in the insulin secretion. The risk of diabetes is increased by 5 folds in women with Polycystic ovarian syndrome. ${ }^{7}$ A threefold increase in risk for gestational diabetes has been shown by a meta-analysis. Carbohydrate metabolism is also affected in PCOS contributing to the development of diabetes. ${ }^{17}$

\section{DYSLIPIDEMIA}

Dyslipidemia is one of the common abnormalities in PCOS women. Decrease in HDL and increase in triglycerides are the common abnormalities noted in metabolic syndrome. Recent studies have shown that mild hypercholesterolemia has been noted in most of the women with PCOS. Insulin resistance in the adipocytes causes shunting of free fatty acids to the liver which in turn causes production of more VLDL (very high density lipoproteins) in the liver leading to lipid abnormalities and atherogenic dyslipidemia. PCOS also leads to release of inflammatory mediators like cytokines and tumour necrosis factor $\alpha$ which inactivates the insulin receptors in the adipose cells. This inhibits the adiponectin release and increases the lipolysis causing release of excessive free fatty acids. ${ }^{18}$

\section{HYPERTENSION}

The occurrence of hypertension in PCOS is still not clear. But few studies have shown the association between PCOS and hypertension. ${ }^{19}$ Excess production of free fatty acids due to insulin resistance causes vasoconstriction and decrease in insulin production causes loss of vasodilatation effect contributing to the development of hypertension. Alteration in the renin angiotensin aldosterone system also causes endothelial dysfunction and results in hypertension. Angiotensin II that is produced by the adipose tissue activates NADP (nicotinamide adenine dinucleotide phosphate) and releases reactive oxygen species (ROS). This ROS causes endothelial injury, platelet aggregation and fibroblast proliferation causing hypertension. ${ }^{20}$

\section{CARDIO METABOLIC RISKS}

The risk of coronary artery disease and stroke are increased two fold in PCOS women. ${ }^{21}$ Various echocardiographic studies have shown that PCOS women have abnormal myocardial function with increased left ventricular mass and increased left ventricular stiffness. Hyperandrogenism has proven to be associated with cardio metabolic risks in PCOS women. Activation of inflammatory mediators, neuro-hormonal involvement and insulin resistance are the common causes of metabolic syndrome progressing to cardiovascular disease. Obesity increases the Leptin levels and thereby increases the cardiovascular risks. Adiponectin which is a protective factor against diabetes and hypertension is decreased in PCOS due to increase in adipose tissue mass. Fat cells release inflammatory cytokines which also plays a role in the development of cardiovascular risk. ${ }^{22}$

\section{VASCULAR RISKS}

Increased arterial stiffness has been noted in women with PCOS. ${ }^{23}$ Micro vascular and macro vascular endothelial dysfunction leads to atherosclerosis in PCOS women. But the vascular risks are mostly associated with insulin resistance rather than PCOS as such. Interleukin 6 is a cytokine produced by adipocytes and it leads to release of acute phase reactants in the hepatic cells like C-reactive protein (CRP). This increases the fibrinogen levels and causes a prothrombic state. Fibrinolysis inhibitor levels 
are also increased causing hypo fibrinolysis in women with polycystic ovary syndrome and leads to atherosclerosis. Coagulation factors like thrombomodulin, Von Willibrands factor, factor VII C, D-dimer and fibrinogen are increased in PCOS. Obesity and insulin resistance results in systemic oxidative stress leading to tissue fibrosis and decreased atherogenic properties. $^{24}$

\section{SCREENING FOR CARDIO METABOLIC RISKS}

All the women with PCOS should be screened for cardio metabolic risks as the long term complications are life threatening. At the time of initial diagnosis of PCOS, OGTT (oral glucose tolerance test) with 75-g glucose should be done. Fasting glucose and HbAlc can be considered when OGTT is not feasible. Fasting lipid profile also should be done at the first visit. If the values are normal, annual screening for high risk women and every three to five years once in those women without any other associated risk factors should be carried out. ${ }^{25}$

\section{MANAGEMENT OF METABOLIC SYNDROME}

Clinicians should also focus on managing metabolic abnormalities apart from treating PCOS alone as the incidence of metabolic abnormalities is on the rise. Management of metabolic syndrome should include both lifestyle modifications and pharmacological interventions.

Lifestyle modifications should include weight reduction of at least 5 to $10 \%$. Few studies have shown that a decrease in weight of about $5-10 \%$ shows an improvement in the metabolic risk. Weight reduction also significantly reduces the risk of cardiovascular diseases and diabetes. Aerobic exercises should be advised earlier for women with PCOS. Diet having low glycaemic value and low fat diet should be advised. They should be encouraged to take legumes and fish as it has omega fatty acids which help in decreasing the metabolic risks. ${ }^{26}$

Pharmacological interventions include Statins which is used to treat dyslipidemia by decreasing the oxidative stress, inflammation, hyper androgenemia and other metabolic derangements. Antiplatelet drugs are used to decrease the prothrombotic risks. Insulin sensitizers like metformin improves the insulin sensitivity and decreases the risk of diabetes. Anti-obesity agents like orlistat can be used to enhance the weight reduction. Bariatric surgery is the last resort in weight reduction and it helps in restoring the hypothalamic pituitary ovarian axis thus correcting the PCOS pathology and its metabolic side effects. ${ }^{27}$ Nicotinic acid and Vitamin D therapy are also shown to decrease the cardiovascular risks but these are still under research. Various natural agents like omega fatty acids (fish oil), broccoli, cardamom, fenugreek, cinnamon, grapes, ginger and onions are also shown to decrease the metabolic risks but these are used only as adjuvants. $^{28}$

\section{CONCLUSION}

PCOS women are at increased risk of developing cardiovascular diseases, diabetes mellitus, metabolic abnormalities, reproductive problems and psychological disturbances affecting their daily life. Late complications of metabolic syndrome should be kept in mind at the time of initial diagnosis of PCOS and screening should be done for cardio metabolic risks and diabetes mellitus. Early screening, timely intervention and proper management will prevent several long term complications of metabolic syndrome.

\section{Funding: No funding sources Conflict of interest: None declared Ethical approval: Not required}

\section{REFERENCES}

1. Trikudanathan S. Polycystic ovarian syndrome. Med Clin North Am. 2015;99(1):221-35.

2. Rasquin Leon LI, Mayrin JV. Polycystic Ovarian Disease. Treasure Island (FL): StatPearls Publishing; 2020.

3. Ndefo UA, Eaton A, Green MR. Polycystic ovary syndrome: a review of treatment options with a focus on pharmacological approaches. Pharmac Therapeut. 2013;38(6):336.

4. Ding DC, Chen W, Wang JH, Lin SZ. Association between polycystic ovarian syndrome and endometrial, ovarian, and breast cancer: A population-based cohort study in Taiwan. Medicine. 2018;97(39).

5. Pelusi B, Gambineri A, Pasquali R. Type 2 diabetes and the polycystic ovary syndrome. Minerva Ginecol. 2004;56(1):41-51.

6. Rojas J, Chávez M, Olivar L, Rojas M, Morillo J, Mejías J, Calvo M, Bermúdez V. Polycystic ovary syndrome, insulin resistance, and obesity: navigating the pathophysiologic labyrinth. Int $\mathbf{J}$ Reproduct Medic. 2014;2014.

7. Chandrasekaran S, Sagili H. Metabolic syndrome in women with polycystic ovary syndrome. Obstet Gynaecolo. 2018;20(4):245-52

8. Glueck CJ, Goldenberg N. Characteristics of obesity in polycystic ovary syndrome: etiology, treatment, and genetics. Metabolism. 2019;92:108-20.

9. Wang ET, Calderon-Margalit R, Cedars MI, Daviglus ML, Merkin SS, Schreiner PJ, Sternfeld B, Wellons M, Schwartz SM, Lewis CE, Williams OD. Polycystic ovary syndrome and risk for long-term diabetes and dyslipidemia. Obstet Gynecol. 2011;117(1):6.

10. Swarup S, Goyal A, Grigorova Y, et al. Metabolic Syndrome. In: StatPearls. Treasure Island: StatPearls Publishing; 2020.

11. Takamiya T, Zaky WR, Edmundowics D, Kadowaki $\mathrm{T}$, Ueshima H, Kuller LH, et al. World Health Organization-defined metabolic syndrome is a better predictor of coronary calcium than the adult 
treatment panel III criteria in American men aged 40-49 years. Diabet Car. 2004;27(12):2977-9.

12. Saif-Ali R, Kamaruddin NA, Molham AH, Al-Dubai SA, Ngah WZ. Relationship of metabolic syndrome defined by IDF or revised NCEP ATP III with glycemic control among Malaysians with Type 2 Diabetes. Diabetol Metabol Syndro. 2020;12(1):1-7.

13. Rajska A, Buszewska-Forajta M, Rachoń D, Markuszewski MJ. Metabolomic insight into polycystic ovary syndrome-An overview. Int J Molecul Sci. 2020;21(14):4853.

14. Fenwick PH, Jeejeebhoy K, Dhaliwal R, Royall D, Brauer P, Tremblay A, Klein D, Mutch DM. Lifestyle genomics and the metabolic syndrome: A review of genetic variants that influence response to diet and exercise interventions. Crit Rev Food Sci Nutr. 2019;59(13):2028-39.

15. Khan Y, Lalchandani A, Gupta AC, Khadanga S, Kumar S. Prevalence of metabolic syndrome crossing $40 \%$ in Northern India: Time to act fast before it runs out of proportions. J Fam Medicine Prim Care. 2018;7(1):118.

16. De Meyts $P$. The insulin receptor and its signal transduction network. InEndotext. 2016.

17. Foroozanfard F, Moosavi SG, Mansouri F, Bazarganipour F. Obstetric and neonatal outcome in PCOS with gestational diabetes mellitus. J Fam Reproduct Heal. 2014;8(1):7.

18. Kim JJ, Choi YM. Dyslipidemia in women with polycystic ovary syndrome. Obstet Gynecol Sci. 2013;56(3):137-42.

19. Amiri M, Tehrani FR, Behboudi-Gandevani S, Bidhendi-Yarandi R, Carmina E. Risk of hypertension in women with polycystic ovary syndrome: a systematic review, meta-analysis and meta-regression. Reproduct Biol Endocrinol. 2020;18(1):1-5.

20. Ożegowska K, Bogacz A, Bartkowiak-Wieczorek J, Seremak-Mrozikiewicz A, Pawelczyk L. Association between the angiotensin converting enzyme gene insertion/deletion polymorphism and metabolic disturbances in women with polycystic ovary syndrome. Molecul Medic Rep. 2016;14(6):5401-7.

21. De Groot PC, Dekkers OM, Romijn JA, Dieben SW, Helmerhorst FM. PCOS, coronary heart disease, stroke and the influence of obesity: a systematic review and meta-analysis. Hum Reproduct Update. 2011;17(4):495-500.

22. Ohashi K, Ouchi N, Matsuzawa Y. Adiponectin and hypertension. Am J Hypertens. 2011;24(3):263-9.

23. Sasaki A, Emi Y, Matsuda M, Kamada Y, Chekir C, Hiramatsu Y, Nakatsuka M. Increased arterial stiffness in mildly-hypertensive women with polycystic ovary syndrome. J Obstet Gynaecol Res. 2011;37(5):402-11.

24. Mannerås-Holm L, Baghaei F, Holm G, Janson PO, Ohlsson C, Lönn M, Stener-Victorin E. Coagulation and fibrinolytic disturbances in women with polycystic ovary syndrome. J Clinic Endocrinol Metabol. 2011;96(4):1068-76.

25. Studen KB, Pfeifer M. Cardiometabolic risk in polycystic ovary syndrome. Endocr Connect. 2018;7(7):R238-51.

26. Dalle Grave R, Calugi S, Centis E, Marzocchi R, El Ghoch M, Marchesini G. Lifestyle modification in the management of the metabolic syndrome: achievements and challenges. Diabet Metabol Syndrom Obes. 2010;3:373.

27. Marvasti TB, Adeli KH. Pharmacological management of metabolic syndrome and its lipid complications. J Pharmaceut Sci. 2010;18(3):146.

28. Srinivasan K. Dietary spices as beneficial modulators of lipid profile in conditions of metabolic disorders and diseases. Food Funct. 2013;4(4):503-21.

Cite this article as: Kalaivani V, Gopalan U.

Metabolic syndrome in polycystic ovary syndrome: a review. Int J Reprod Contracept Obstet Gynecol 2021;10:1247-50. 